www.nature.com/ejhg

\title{
Paradoxes in longevity: sequence analysis of mtDNA haplogroup J in centenarians
}

\author{
Giuseppina Rose ${ }^{1}$, Giuseppe Passarino ${ }^{1}$, Giuseppina Carrieri ${ }^{1}$, Katia Altomare ${ }^{1}$, \\ Valentina Greco $^{1}$, Stefano Bertolini ${ }^{2}$, Massimiliano Bonafè ${ }^{3}$, Claudio Franceschi ${ }^{3,4}$ and \\ Giovanna De Benedictis*,1
}

\author{
${ }^{1}$ Department of Cell Biology, University of Calabria, Rende, Italy; ${ }^{2}$ Department of Internal Medicine, University of \\ Genova, Genova, Italy; ${ }^{3}$ Department of Experimental Pathology, University of Bologna, Bologna, Italy; ${ }^{4}$ National \\ Institute for Aging Research (INRCA), Ancona, Italy
}

Previous studies have shown that mitochondrial DNA (mtDNA) haplogroup J is significantly over-represented in healthy centenarians with respect to younger controls, thus suggesting that this haplogroup predisposes to successful aging and longevity. On the other hand, the same haplogroup is reported to have elevated frequency in some complex diseases. To verify if centenarians clustered in a particular lineage within J we have sequenced the D-loop region from 18 centenarians and 18 younger controls, previously characterized to be J. Then the entire mtDNA molecule was sequenced in a sub-sample of nine centenarians to find possible functional mutations associated with haplogroup $\mathrm{J}$ in successful aging. No clustering of the $J$ haplogroup mtDNA from centenarians was observed. In addition, most of the mutations found are known as diseaseassociated mutations. The general picture that emerges from the study is that the $J$ haplogroup of centenarians is surprisingly similar to that found in complex diseases, as well as in Leber Hereditary Optic Neuropathy. This finding implies that the same mutations could predispose to disease or longevity, probably according to individual-specific genetic backgrounds and stochastic events. This data reveals another paradox of centenarians and confirms the complexity of the longevity trait. European Journal of Human Genetics (2001) 9, $701-707$.

Keywords: aging; longevity; mitochondrial DNA

\section{Introduction}

Much evidence has accumulated that mitochondrial DNA (mtDNA) is associated with the aging process. ${ }^{1}$ It was first recognized that somatic mutations accumulate during aging, ${ }^{2}$ suggesting that dysfunction of mtDNA, which is essential in the energy balance of the cell, but which also is responsible for most of the endogenous free radicals and for apoptosis regulation, may play a role in the pathophysiology of aging and senescence. ${ }^{3}$ On the other hand, increasing evidences indicate that mtDNA inherited variability plays a

*Correspondence: G De Benedictis, Department of Cell Biology, University of Calabria. 87030 Rende, Italy.

Tel. +39 0984 492932; Fax +39 0984 492911;

E-mail g.debenedictis@unical.it

Received 20 March 2001; revised 6 June 2001; accepted 28 June 2001 role in successful aging and longevity. ${ }^{4-7}$ Recently it was observed that in Italy the population pool of mtDNA haplogroups is different between healthy centenarians and young individuals, the main difference being sustained by the $\mathrm{J}$ haplogroup whose frequency increased from $2 \%$ in controls to about $20 \%$ in male centenarians. ${ }^{8}$ This observation prompted us to suggest that haplogroup $\mathrm{J}$ may be associated with longevity. This inference was subsequently confirmed by a different statistic and demographic approach to the data that takes into account the mortality trajectories of the studied population. ${ }^{9}$ In addition, this finding has been recently confirmed in human longevity studies carried out in Northern Irish population, where a J subgroup was found to be over-represented in centenarians with respect to younger controls..$^{10}$ Intriguingly, J haplogroup is reported to boost the effect of mutations causing a mitochondrial disease, the 
Leber Hereditary Optic Neurophaty (LHON), ${ }^{11}$ and to contribute to optic neuritis in multiple sclerosis patients. ${ }^{12}$ In order to clarify this apparent paradox, first we studied the D-loop region (HVS-I) in mtDNA from 18 healthy centenarians (category A according to the classification given by Franceschi et al. ${ }^{13}$ ) and 18 younger controls previously characterized as $\mathrm{J}$, to verify if centenarians clustered in a particular lineage within $\mathrm{J}$. We then sequenced the whole mtDNA coding region in a sub-sample of nine centenarians, to investigate possible functional mutations associated with haplogroup J in successful aging.

\section{Materials and methods Subjects}

Our samples consisted of 18 healthy centenarians (7 males and 11 females, category A according to the classification given by Franceschi et al. ${ }^{13}$ ) and 18 healthy younger controls (8 males and 10 females) recruited in the previous study. ${ }^{8}$

\section{PCR}

Total DNA was extracted from blood buffy coats following standard procedures. PCR amplification was performed on $300 \mathrm{ng}$ of total DNA in $100 \mu \mathrm{l}$ of reaction mixture containing $200 \mu \mathrm{M}$ of each dNTP, $30 \mathrm{pmol}$ of each primer, $2.5 \mathrm{U}$ of Taq
DNA polymerase and $1.5 \mathrm{~mm} \mathrm{MgCl}_{2}$. The reaction was carried out for a total of 35 cycles in a GeneAmp PCR System 9600 (Perkin Elmer).

The whole mtDNA was amplified in eleven overlapping fragments using the primer pairs and amplification conditions previously described. ${ }^{14}$

\section{Sequencing}

PCR-amplified fragments were purified using a QIAquick PCR purification Kit (Qiagen).

The sequences were determined by a fluorescence-based automated direct sequencing technique using a model 310 DNA sequencer with BigDye Terminator Cycle Sequencing Ready Reaction Kit (PE Applied Biosystems).

Sequencing reaction mixtures contained $8 \mu \mathrm{l}$ of Terminator Ready Reaction mix, 300 ng of template, 3.2 pmol of primer in a total volume of $20 \mu \mathrm{l}$. Cycle sequencing was carried out for 25 cycles at $96^{\circ} \mathrm{C}$ for $10 \mathrm{~s}, 50^{\circ} \mathrm{C}$ for $5 \mathrm{~s} .60^{\circ} \mathrm{C}$ for $4 \mathrm{~min}$ in a GenAmp PCR system 9600. The extention products were purified using the Centri-Sep ${ }^{(i \times}$ spin columns (Princeton Separations).

\section{Network analysis}

The phylogenetic relationships among the sequences were calculated with the program Network 2.0. ${ }^{15,16}$

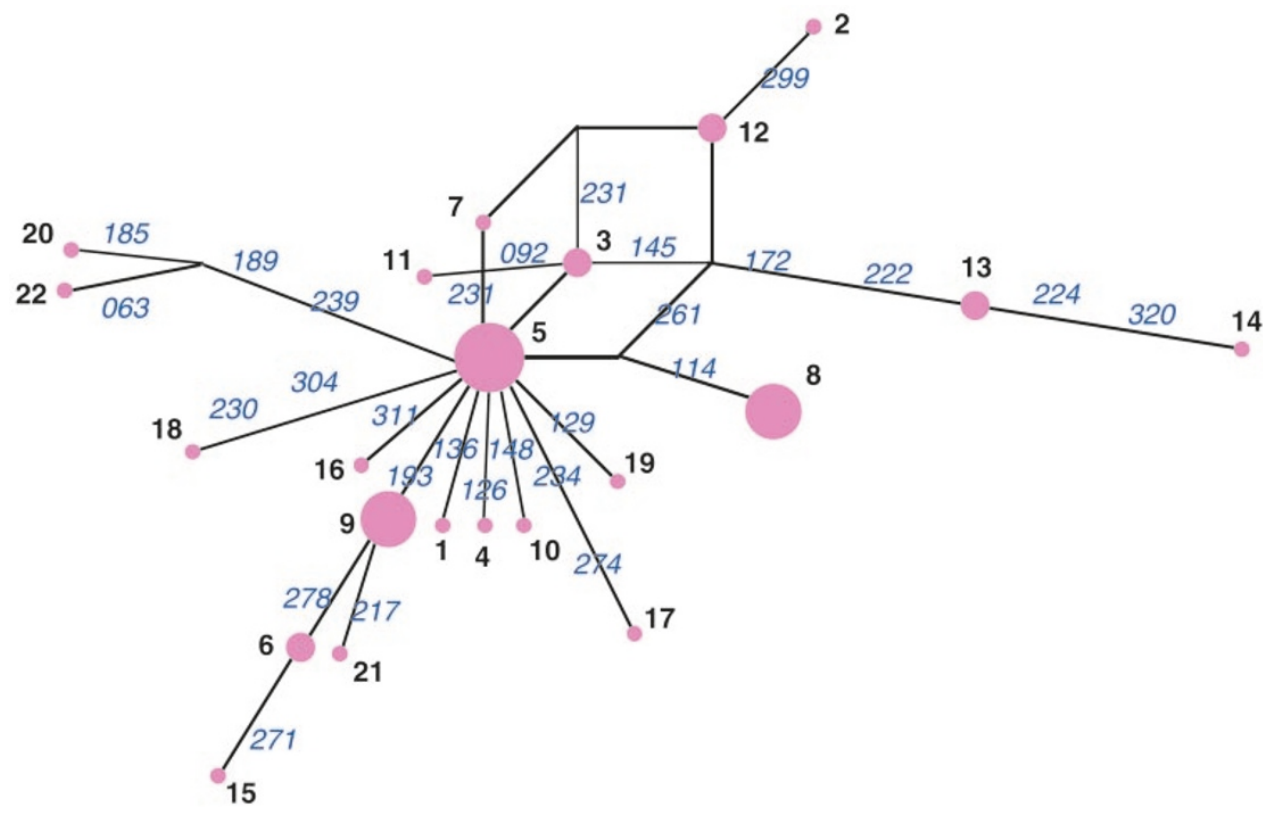

Figure 1 Median Network of the HVSI haplotypes. The mutations are shown in italics. The position of the mutations are given according to Anderson et al. ${ }^{18}$ less 16000 . The haplotype identification number is shown in bold. The radius of the circles indicating each haplotype is proportional to the number of individuals. Controls and Centenarians (with the respective identification number) are denoted $\mathrm{C}$ and $\mathrm{L}$ respectively. The samples were grouped as follows: Ht (Haplotype) 1: C107; Ht 2: C 224; Ht 3: C 225, C 366; Ht 4: C 258; Ht 5: C 259, L125, L174, L175, L216; Ht 6: C 261; Ht 7: C 265; Ht 8: C 287, C 322, C 323, C 25; Ht 9: C 330, C 34, L18, L84; Ht 10: C 22; Ht 11: C 16; Ht 12: C 26, L 92; Ht 13: L7, L 170; Ht 14: L 21; Ht 15: L 24; Ht 16: L 32; Ht 17: L 105; Ht 18: L 107; Ht 19: L 116; Ht 20: L 121; Ht 21: L 172; Ht 22: L 224. The Median Network was calculated with Network 2.0 ${ }^{15,16}$ which is available at: http:// www.fluxus-engineering.com. 
Table 1 Variant sites found in mtDNA non-coding region (HVS I) from centenarians (L) and controls (C) of haplogroup J

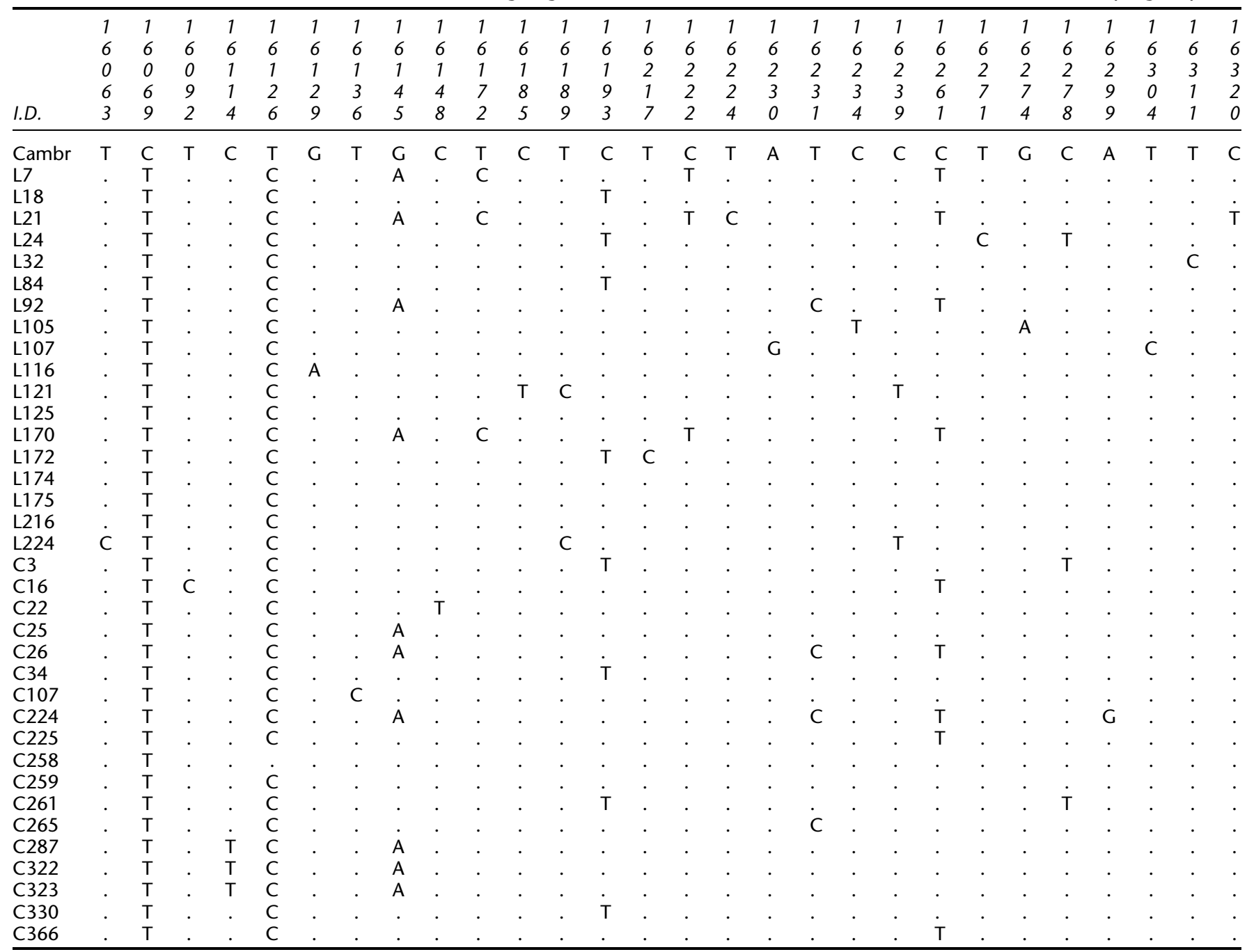

I.D., sample identification number. Cambridge reference sequence ${ }^{18,19}$

\section{Results}

Table 1 reports D-loop sequences by which the Median Network $^{15,16}$ shown in Figure 1 is obtained. The centenarian samples did not show particular clustering respective to the controls. Interestingly two branches (types 13, 14 and types 20, 22), until now not found in southern Europeans, ${ }^{17}$ were observed in three and two centenarians respectively.

Fifty-four variant sites were found in the mtDNA coding region with respect to the reference sequence, ${ }^{18,19}$ which is known to be part of the $\mathrm{H}$ haplogroup (Table 2). Fifteen sites were present in all the centenarians. Out of these, nine variants were distinctive of haplogroup $\mathrm{H}$ or rare polymorphisms of the reference sequence. ${ }^{18,19}$ Out of the six remaining variants, four were missense mutations: the 13708A in ND5 gene $\left(\mathrm{Ala}_{458}>\mathrm{Thr}_{458}\right)$ is restricted to $\mathrm{J}$; the $10398 \mathrm{G}$ in ND3 gene $\left(\mathrm{Thr}_{114}>\mathrm{Ala}_{114}\right)$ characterizes the European haplogroups I, J and K; the 4216C in ND1 gene $\left(\mathrm{Tyr}_{304}>\mathrm{His}_{304}\right)$ and the $15452 \mathrm{~A}$ in cytochrome $\mathrm{b}$ gene $\left(\mathrm{Leu}_{236}>\mathrm{IsO}_{236}\right)$, are shared by $\mathrm{J}$ and $\mathrm{T}$ haplogroups. ${ }^{20}$ The first mutation changes a moderately conserved aminoacid, with vertebrates having either Ala or Leu at this position. ${ }^{21}$ The other three mutations change weakly conserved aminoacids. The Median Network constructed by the nine sequences is shown in Figure 2. No reticulations were observed. Two branches are easily recognized. This bifurcation was previously highlighted by the ACCI restriction site at 15257, which defines the subhaplogroups $\mathrm{J} 1$ and J2. ${ }^{11}$ One branch (corresponding to J1) is characterized by the mutation 3010A, which occurs in 16SRNA gene, close to the CAP binding site, in an evolutionary highly conserved region. ${ }^{22}$ The other branch is characterized by five associated mutations: 5633T, 7476T, 10172A (silent), 15257A and 15812A. The 5633T and the $7476 \mathrm{~T}$ occur in the anticodon region of tRNA ${ }^{\text {Ala }}$ and $t R N A^{\text {Ser }}$ genes respectively. Both these mutations may induce changes 
Table 2 Variant sites found in mtDNA coding region from centenarians (L)

\begin{tabular}{|c|c|c|c|c|c|c|c|c|c|c|c|c|c|c|}
\hline \multirow[b]{3}{*}{ Cambr } & \multicolumn{2}{|c|}{$12 S$} & \multicolumn{6}{|c|}{$16 \mathrm{~S}$} & \multirow{3}{*}{$\begin{array}{c}N D 1 \\
4216^{*} \\
T\end{array}$} & \multicolumn{2}{|c|}{ ND2 } & \multirow{3}{*}{$\begin{array}{c}A \\
5633 \\
C\end{array}$} & \multirow{3}{*}{$\begin{array}{c}\mathrm{COI} \\
7028 \\
\mathrm{C}^{* *}\end{array}$} & \multirow{3}{*}{$\begin{array}{c}S \\
7476 \\
C\end{array}$} \\
\hline & 750 & 1438 & 2158 & 2392 & 2404 & 2706 & 2789 & 3010 & & 4769 & 5460 & & & \\
\hline & $A^{* *}$ & $A^{* *}$ & $T$ & $T$ & $T$ & $A^{* *}$ & C & G & & $A^{* *}$ & G & & & \\
\hline L170 & G & G & C & - & - & G & - & A & C & G & A & - & $\mathrm{T}$ & - \\
\hline L21 & G & G & C & - & - & G & - & A & C & G & A & - & $\mathrm{T}$ & - \\
\hline L92 & G & G & - & C & - & G & - & - & C & G & - & - & $\mathrm{T}$ & $\mathrm{T}$ \\
\hline L107 & G & G & - & - & - & G & - & A & C & G & - & - & $\mathrm{T}$ & - \\
\hline L116 & G & G & - & - & - & G & - & - & C & G & - & $\mathrm{T}$ & $\mathrm{T}$ & $\mathrm{T}$ \\
\hline L24 & G & G & - & - & - & G & - & - & C & G & - & $\mathrm{T}$ & $\mathrm{T}$ & $\mathrm{T}$ \\
\hline L32 & G & G & - & - & - & G & - & A & C & G & - & - & $\mathrm{T}$ & - \\
\hline L84 & G & G & - & - & C & G & - & - & C & G & - & $\mathrm{T}$ & $\mathrm{T}$ & $\mathrm{T}$ \\
\hline \multirow[t]{3}{*}{ L18 } & G & G & - & - & - & G & $\mathrm{T}$ & - & C & G & - & $\mathrm{T}$ & $\mathrm{T}$ & $\mathrm{T}$ \\
\hline & \multicolumn{2}{|c|}{ COII } & NC & \multicolumn{4}{|c|}{ ATPase 6} & \multicolumn{2}{|c|}{ COII } & \multicolumn{3}{|c|}{ ND3 } & \multicolumn{2}{|c|}{$R$} \\
\hline & 7786 & 7789 & 8269 & 8557 & 8738 & 8760 & 8860 & 9656 & 9872 & 10172 & 10389 & $10398^{*}$ & 10410 & 10454 \\
\hline Cambr & C & G & G & G & $T$ & $T$ & $A^{* *}$ & $T$ & $A$ & G & $T$ & A & $T$ & $T$ \\
\hline L170 & - & - & A & A & - & - & G & - & - & - & - & G & C & - \\
\hline L21 & - & - & A & A & - & - & G & - & - & - & - & G & - & - \\
\hline L92 & - & A & - & - & - & - & G & - & - & - & - & G & - & - \\
\hline L107 & T & - & - & - & C & - & G & - & - & - & - & G & - & - \\
\hline L116 & - & - & - & - & - & - & G & - & - & A & - & G & - & C \\
\hline L24 & - & - & - & - & - & - & G & C & - & A & - & G & - & - \\
\hline L32 & - & - & - & - & - & C & G & - & - & - & - & G & - & - \\
\hline L84 & - & - & - & - & - & - & G & - & - & A & C & G & - & - \\
\hline \multirow[t]{3}{*}{ L18 } & - & - & - & - & - & - & G & - & G & A & - & G & - & - \\
\hline & $N D 4 L$ & & & ND4 & & & \multicolumn{8}{|c|}{ ND5 } \\
\hline & 10499 & 11251 & 11377 & 11506 & 11719 & 12007 & 12358 & 12612 & 12903 & $13708^{*}$ & 13722 & 13821 & 13879 & 13934 \\
\hline Cambr & A & A & G & $T$ & $G^{* *}$ & G & A & A & $T$ & G & A & C & $T$ & C \\
\hline L170 & - & G & - & - & A & A & - & G & - & A & - & - & C & - \\
\hline L21 & - & G & - & - & A & A & - & G & - & A & - & - & C & - \\
\hline L92 & G & G & A & - & A & - & - & G & - & A & G & - & - & - \\
\hline L107 & - & G & - & - & A & - & - & G & - & A & - & - & - & $\mathrm{T}$ \\
\hline L116 & - & G & - & - & A & - & - & G & C & A & - & - & - & - \\
\hline L24 & - & G & - & - & A & - & - & G & - & A & - & - & - & - \\
\hline L32 & - & G & - & C & A & - & G & G & - & A & - & - & - & $\mathrm{T}$ \\
\hline L84 & - & G & - & - & A & - & - & G & - & A & - & - & - & - \\
\hline \multirow[t]{3}{*}{ L18 } & - & G & - & - & A & - & - & G & - & A & - & $\mathrm{T}$ & - & - \\
\hline & ND5 & ND6 & & & & & Cytb & & & & & $T$ & & \\
\hline & 14133 & 14554 & 14766 & 14798 & 15067 & 15227 & 15257 & 15326 & $15452^{*}$ & 15788 & 15812 & 15942 & & \\
\hline Cambr & $A$ & A & $C^{* *}$ & $T$ & $T$ & G & G & $A^{* *}$ & C & $A$ & G & $T$ & & \\
\hline L170 & - & - & $\mathrm{T}$ & - & C & - & - & $G$ & A & - & - & - & & \\
\hline L21 & - & - & $\mathrm{T}$ & - & - & - & - & $G$ & A & $G$ & - & - & & \\
\hline L92 & G & - & $\mathrm{T}$ & - & - & - & A & G & A & - & - & - & & \\
\hline L107 & - & - & $\mathrm{T}$ & C & - & A & - & G & A & - & - & - & & \\
\hline L116 & - & - & $\mathrm{T}$ & - & - & - & $A$ & G & $A$ & - & $A$ & C & & \\
\hline L24 & - & G & $\mathrm{T}$ & - & - & - & A & G & A & - & A & - & & \\
\hline L32 & - & - & $\mathrm{T}$ & C & - & - & - & G & A & - & - & - & & \\
\hline L84 & - & - & $\mathrm{T}$ & - & - & - & A & G & A & - & A & - & & \\
\hline L18 & - & - & $\mathrm{T}$ & - & - & - & A & $G$ & A & - & A & - & & \\
\hline
\end{tabular}

*-haplogroup missense mutations. ${ }^{* *}$ Distinctive variants and rare polymorphisms of the Cambridge (Cambr) reference sequence. ${ }^{18,19} 12 \mathrm{~S}, 12 \mathrm{~S}$ rRNA; 16S, 16 S rRNA; ND1, NADH dehydrogenase 1; ND2, NADH dehydrogenase 2; A, tRNA-Alanine; COI, Cytochrome c oxidase I; S, tRNASerine; COII, Cytochrome c oxidase II; NC, non coding Z; ATPase 6, ATP synthase 6; COIII, Cytochrome c oxidase III; ND3, NADH dehydrogenase 3; R, tRNA-Arginine; ND4L, NADH dehydrogenase 4L; ND4, NADH dehydrogenase 4; ND5, NADH dehydrogenase 5; ND6, NADH dehydrogenase 6; Cytb, Cytochrome b; T, tRNA-Threonine.

in the three-dimensional structure of the relevant tRNAs, and affect their functionality. The mutations 15257A (As$\left.\mathrm{p}_{171}>\mathrm{Asn}_{171}\right)$ and $15812 \mathrm{~A}\left(\mathrm{Val}_{356}>\mathrm{Met}_{356}\right)$ occur in the cytochrome $b$ gene. The first one changes a highly conserved aminoacid, and probably affects the efficiency of this key electron carrier. $^{21}$

\section{Discussion}

In order to better understand how mtDNA haplogroup J could be associated to longevity ${ }^{8}$ we have sequenced the mtDNA-D-loop in a sample of centenarians and young controls plus the coding mtDNA region in a subset of centenarians, all categorized as J. 


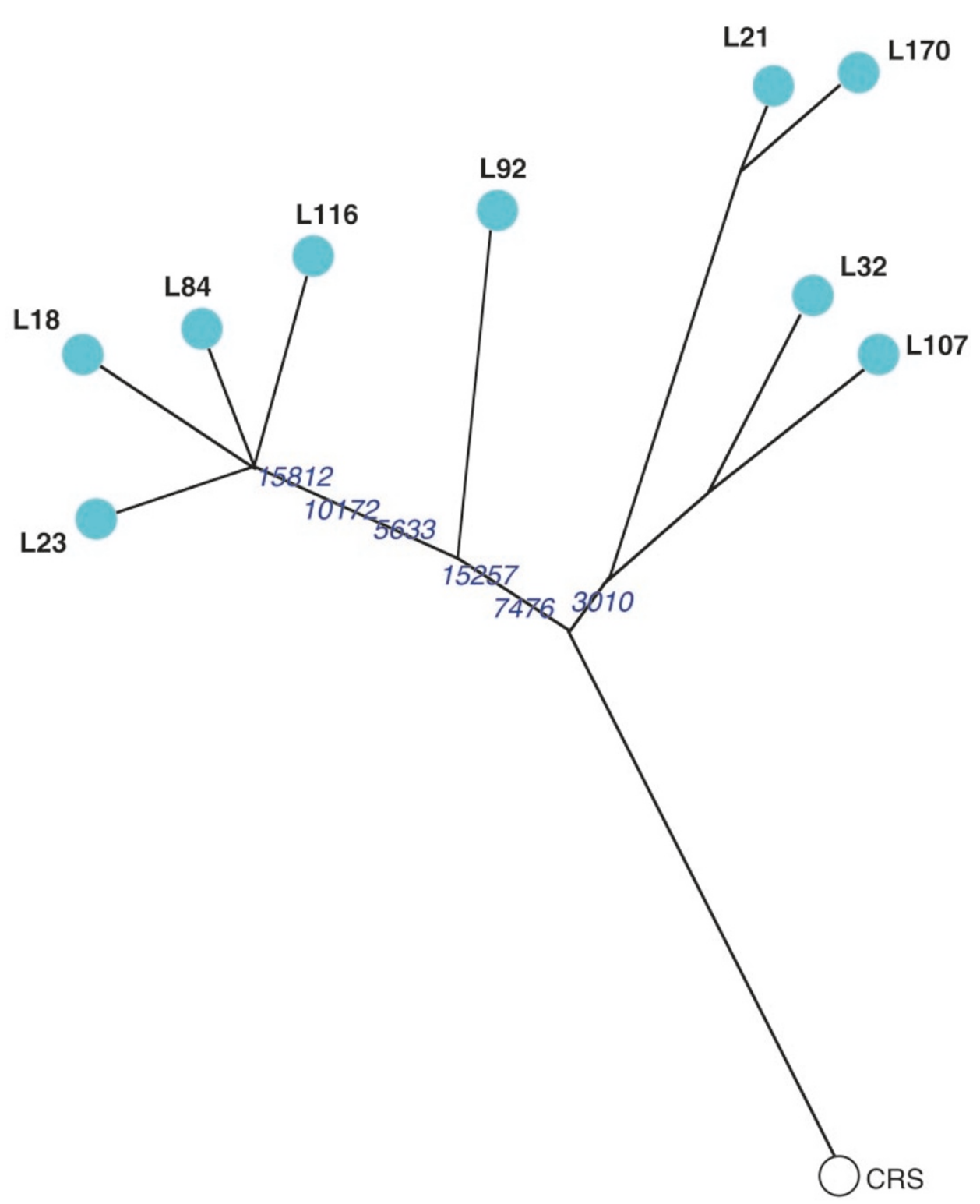

Figure 2 Median Network of the mitochondrial coding region sequences in centenarians (L). The mutations designating the two major branches are shown in italics. The position of the mutations are given according to Anderson et al. ${ }^{18}$ CRS denotes Cambridge Reference Sequence.

At the analysis of the D-loop (Table 1 and Figure 1) the centenarians did not show any reduction in variation, and actually they were even more diverse than controls, thus ruling out the possibility that, by chance, we sampled a group of closely related centenarians. In addition, the lack of clustering among centenarians indicated that the high frequency of $J$ is not due to a specific haplotype falling in this group but to mutations which characterize the whole, or at least a large part of, haplogroup.

The two branches of the network constructed with the coding region sequence (Table 2 and Figure 2), are intrigu- ingly characterized by mutations previously associated to complex diseases where mtDNA involvement has been proposed. An exciting example is given by the mutation 3010A that defines one of the two branches of Figure 2. This mutation has been found associated with longevity not only in Italians (present study), but also in Japanese. ${ }^{4}$ However the 3010A occurs also in patients affected by mitochondrial pathologies, even if other mutations have been proposed to be the pathogenic ones. ${ }^{23-26}$ Moreover, the complete sequence of mtDNA in a family with $\mathrm{LHON}^{27}$ showed that it was characterized by the $3010 \mathrm{~A}$, besides the causative 
mutation at 11778 . Similarly, the haplotype defined by the mutations 5633T, 7476T, 15812A has been reported as risk factor in Alzheimer's disease. ${ }^{28}$ On the whole, the general picture which emerges from these results is that the $\mathrm{J}$ haplogroup of centenarians is surprisingly similar to that found associated with several complex diseases. ${ }^{11,12,28,29}$

How could this apparent paradox be explained? The nonrandom associations recently observed between mitochondrial and nuclear polymorphisms in some complex traits ${ }^{30,31}$ give some hints, suggesting that complex interactions between mtDNA and nuclear genes play a role on the susceptibility to develop longevity or disease. Indeed a relationship exists between oxidative phosphorylation (OXPHOS) performance and mtDNA haplogroups, with haplogroup T showing a significantly less efficient OXPHOS with respect to $\mathrm{H}^{32}$ The mutations defining haplogroup J occur in complex I protein subunits and are partly shared with haplogroup T. Previously it has been proposed that such mutations could impair the OXPHOS performance, putting the cell in a vulnerable situation where a further mutation (such as the LHON at 11778) would be more likely to be harmful. ${ }^{11,33}$ However, a low OXPHOS performance may not necessarily be detrimental for the cell. In fact, it was recently shown that an OXPHOS decrease produces increase of Reactive Oxygen Species (ROS), which in turn induce, in a tissue specific way, over-expression of nuclear genes coding for detoxifying enzymes. ${ }^{34}$ Similar results had been previously reported also in yeast, where it was observed that mutant strains of Saccharomyces cerevisiae carrying mtDNA damages were able to up-regulate the expression of stressresponder genes, leading the mutant strains to live longer than the normal ones. ${ }^{35}$ In this scenario, a certain mtDNA inherited mutation could induce longevity or disease according to the individual-specific genetic background as well as to stochastic events.

The case of the mtDNA $\mathrm{J}$ haplogroup is not the first apparent paradox found while studying centenarians, where alleles supposedly risk-bearer for many genes ${ }^{36-41}$ have been found at frequencies similar, or even higher, to those found in the younger population. In any case, the mtDNA sequence analyses carried out in subjects characterized by successful aging and longevity reveal another paradox of centenarians and confirm the complexity of the longevity trait.

\section{Acknowledgments}

Work financed by Italian Ministry of University \& Scientific and Technology Research (MURST Project: Genetics factors involved in human aging and longevity, 2000-2002), by National Institute for Aging Research, INRCA (contract to GD Benedictis) and by the Ellison Medical Foundation.

\section{References}

1 Wallace DC: Mitochondrial diseases in man and mouse. Science 1999; 283: $1482-1488$.
2 Cortopassi GA, Shibata D, Soong NW, Arnheim N: A pattern of accumulation of a somatic deletion of mitochondrial DNA in aging human tissue. Proc Natl Acad Sci USA, 89, 7370-7374.

3 Gadaleta MN, Kadenbach B, Lezza AMS et al: Aged-linked changes in the genotype and phenotype of mitochondria. In: S.Papa et al., (eds): Frontiers in Cellular Bionergetics. New York: Kluwer Academic/Plenum publishers, 1999, 693- 727.

4 Tanaka M, Gong JS, Znang J, Yonada M, Yagi K: Mitochondrial genotype associated with longevity. Lancet 1998; 351: 185-186.

5 Ivanova R, Lepage V, Charron D, Schächter F: Mitochondrial genotype associated with French Caucasian centenarians. Gerontol 1998; 44: 349.

6 Korpelainen H. Genetic maternal effect on human life span through the inheritance of mitochondrial DNA. Hum Hered 1999; 49: $183-185$.

7 De Benedictis G, Carrieri G, Varcasia O, Bonafè M, Franceschi C: Inherited variability of the mitochondrial genome and successful aging in humans. Ann NY Acad Sci 2000; 908: 208-218.

8 De Benedictis G, Rose G, Carrieri G et al: Mitochondrial DNA inherited variants are associated with successful aging and longevity in humans. Faseb J 1999; 13: 1532-1536.

9 Yashin AI, De Benedictis G, Vaupel JW et al: Genes, demography, and life span: the contribution of demographic data in genetic studies on aging and longevity. Am J Hum Genet 1999; 65: 1178 1193.

10 Ross OA, McCormack R, Curran MD et al: Mitochondrial DNA Polymorphism: Its role in longevity of the Irish Population. Exp Gerontol 2001; In Press.

11 Torroni A, Petrozzi M, D'Urbano L et al: Haplotype and phylogenetic analyses suggest that one European-specific mtDNA background plays a role in the expression of Leber hereditary optic neuropathy by increasing the penetrance of the primary mutations 11778 and 14484. Am J Hum Genet 1997; 60 : $1107-1121$.

12 Reynier P, Penisson-Besnier I, Moreau C et al: MtDNA haplogroup J: a contributing factor of optic neuritis. Europ J Hum Genet 1999; 7: 404-406.

13 Franceschi C, Motta L, Valensin S et al: Do men and women follow different trajectories to reach extreme longevity? Aging Clin Exp Res 2000; 12: $77-84$

14 Passarino G, Semino O, Modiano G, Santachiara-Benerecetti AS: COII/tRNA(Lys) intergenic 9-bp deletion and other mtDNA markers clearly reveal that the Tharus (southern Nepal) have Oriental affinities. Am J Hum Genet 1993; 53: 609-618.

15 Bandelt HJ, Forster P, Sykes BC, Richards MB: Mitochondrial portraits of human populations using median networks. Genetics 1995; 14: $743-753$.

16 Rohll A, Mihn DL: Network; a program package for calculating phylogenetic networks. Mathematisches Seminar, University of Hamburg, 1997.

17 Richards MB, Macaulay VA, Bandelt HJ, Sykes BC: Phylogeography of mitochondrial DNA in western Europe. Ann Hum Genet 1998; 62: $241-260$.

18 Anderson S, Bankier AT, Barrell BG et al: Sequence and organization of the human mitochondrial genome. Nature 1981; 290: 457-465.

19 Andrews RM, Kubacka I, Chinnery PF, Lightowlers RN, Turnbull $\mathrm{DM}$, Howell N: Reanalysis and revision of the Cambridge reference sequence for human mitochondrial DNA. Nat Genet 1999; 23: 147

20 Macaulay V, Richards M, Hichey E et al: The emerging tree of West Eurasian mtDNAs: a synthesis of control-region sequences and RFLPs. Am J Hum Genet 1999; 64: 232-249.

21 Brown MD, Voljavec AS, Lott MT, Torroni A, Yang C, Wallace DC: Mitochondrial DNA complex I and III mutation associated with Leber's hereditary optic neuropathy. Genetics 1992; 130: $163-173$

22 Mehta AB, Vulliamy T, Gordon-Smith EC, Luzzatto L: A new genetic polymorphism in the $16 \mathrm{~S}$ ribosomal RNA gene of human mitochondrial DNA. Ann Hum Genet 1989; 53: 303 - 310. 
23 Moraes CT, Ciacci F, Bonilla E, Ionasescu V, Schon EA, Di Mauro S: A mitochondrial tRNA anticodon swapp associated with a muscle disease. Nat Genet 1993; 4: 284-288.

24 Moraes CT, Ciacci F, Bonilla E et al: Two novel pathogenic mitochondrial DNA mutations affecting organelle number and protein synthesis. Is the tRNALeu (UUR) gene an etiologic hot spot? J Clin Invest 1993; 92: 2906-2915.

25 Lertrit P, Noer AS, Jean-Francois MJ et al: A new disease-related mutation for mitochondrial encephalopathy lactic acidosis and stroke like episodes (MELAS) syndrome affects the ND4 subunit of the respiratory complex I. Am J Hum Genet 1992; 51: 457 568.

26 Marzuki S, Noer AS, Lertrit P et al: Normal variants of human mitochondrial DNA and translation products: the building of a reference data base. Hum Genet 1991; 88: 139-145.

27 Wallace DC, Singh G, Lott MT et al: Mitochondrial DNA mutation associated with Leber's hereditary optic neuropathy. Science 1988; 242: 1427 -1430.

28 Chagnon P, Gee M, Filion M, Robitaille Y, Belouchi M, Gauvreau D: Phylogenetic analysis of the mitochondrial genome indicates significant difference between patients with Alzheimer disease and controls in a French-Canadian founder population. Am J Med Genet 1999; 85: 20-30.

29 Hofmann S, Bezold R, Jaksch M et al: Wolfram (DIDMOAD) syndrome and Leber hereditary optic neuropathy (LHON) are associated with distinct mitochondrial DNA haplotypes. Genomics 1997; 39: 8-18.

30 De Benedictis G, Carrieri G, Garasto S et al: Does a retrograde response in human aging and longevity exist? Exp Gerontol 2000; 35: $795-801$.

31 Carrieri G, Bonafè M, De Luca M et al: Mitochondrial DNA haplogroups and APOE4 allele are non-independent variables in sporadic Alzheimer's disease. Hum Genet 2001; 108: 194-198.
32 Ruiz-Pesini E, Lapena AC, Diez-Sanchez C et al: Human mtDNA haplogroups associated with high or reduced spermatozoa motility. Am J Hum Genet 2000; 67: 682-696.

33 Wallace DC, Brown MD, Lott MT: Mitochondrial DNA variation in human evolution and disease. Gene 1999; 238: $211-230$.

34 Esposito LA, Melov S, Panov A, Cottrell BA, Wallace DC: Mitochondrial disease in mouse results in increased oxidative stress. Proc Natl Acad Sci USA 1999; 96: 4820-4825.

35 Kirchman PA, Kim S, Lai CY, Jazwinski MS: Interorganelle signaling is a determinant of longevity in Saccharomyces Cerevisae. Genetics 1999; 152: 179-190.

36 Mannucci PM, Mari D, Merati G et al: Gene polymorphisms predicting high plasma levels of coagulation and fibrinolysis proteins. A study in centenarians. Arterioscler Thromb Vasc Biol 1997; 17: $755-759$.

37 Robine JM, Forette B, Franceschi C, Allard M (Eds): The paradoxes of longevity. Research and perspectives in longevity. New York: Springer-Verlag. 1999.

38 Bonafe M, Olivieri F, Mari D et al: P53 variants predisposing to cancer are present in healthy centenarians. Am J Hum Genet 1999; 64: 292-295.

39 Bonafe M, Olivieri F, Mari D et al: P53 codon 72 polymorphism and longevity: additional data on centenarians from continental Italy and Sardinia. Am J Hum Genet 1999; 65: 1782-1785.

40 Bladbjerg EM, Andersen-Ranberg K, de Maat MP et al: Longevity is independent of common variations in genes associated with cardiovascular risk. Thromb Haemost 1999; 82: 1100-1105.

41 De Benedictis G, Tan Q, Jeune B et al: Recent advances in human gene-longevity association studies. Mech Ageing Dev 2001; 122: 909-920. 